\title{
Past Advances and Future Perspective of Ti-Ta Alloys
}

\author{
Nestor R Florido-Suarez ${ }^{1}$, Amparo Verdu-Vazquez ${ }^{2}$, Pedro P Socorro-Perdomo ${ }^{1}$ and Julia C Mirza-Rosca ${ }^{1 *}$ \\ ${ }^{1}$ Mechanical Eng. Dept., University of Las Palmas de Gran Canaria, Spain \\ ${ }^{2}$ Building Technology Dept., Politecnica University of Madrid, Spain
}

*Corresponding author: Julia C Mirza-Rosca, Mechanical Eng. Dept., University of Las

Palmas de Gran Canaria, Spain.

Received Date: April 19, 2021

Published Date: April 26, 2021

\begin{abstract}
In the case of conventional Ti-based biomaterials, such as Ti-6Al-4V and Nitinol, the release of $\mathrm{Al}, \mathrm{V}$ and Ni has been shown to be detrimental to the human body and in this context, Ti-Ta alloys have been proposed as one of the best options for biomedical devices. The main focus of this study is to review the different chemical composition of manufactured Ti-Ta alloys, their various techniques of fabrication as well as the microstructure, mechanical properties and corrosion resistance. The paper sought to give an idea of the scope of the research and effort that has gone into developing a high-quality titanium medical device.
\end{abstract}

Keywords: Ti-Ta alloys; Arc-melting; Microstructure; Mechanical properties; Corrosion; EIS

\section{Introduction}

The market request for suitable materials for permanent devices in the human body is growing as people live longer and their bones are weakening with age. The most widely used biomaterial today is titanium, whose corrosion resistance is due to the stability of the oxide film that grows on its surface and can be re-formed at human body temperature and in physiological media if injured. The use of Ti and its alloys as biomaterials is increasing due to their reduced modulus, higher biocompatibility, superior strength and increased corrosion resistance compared to conventional biomaterials such as stainless steel and Co-Cr alloys. But in the case of traditional Ti-based biomaterials such as Ti-6Al-4V and Nitinol, the liberation of $\mathrm{Al}, \mathrm{V}$ and $\mathrm{Ni}$ has been shown to be detrimental to the human organism [1,2]. In this context, Ti-Ta alloys have been proposed as one of the best options for biomedical devices due to their exceptional biocompatibility in the human body environment, superior strength, relatively lower elastic moduli and superior corrosion resistance [3-5].

\section{Chemical Composition of Titanium-Tantalum Alloys}

Various types of binary titanium- tantalum alloys have been designed, manufactured and analyzed as follows: Ti-10Ta [6-10]; Ti-20Ta [10]; Ti-30Ta [6-8,10-12]; Ti-40Ta [6,10,12,13]; Ti-50Ta [6,8,10-15]; Ti-60Ta [6,10]; Ti-70Ta [7,10]; Ti-80 Ta $[6,10]$.

\section{Fabrication}

To present date, Ti-Ta alloys were satisfactorily produced by arcmelting [7,11-14,16,17], powder metallurgy [17,18], mechanical alloying [19,20] and additive manufacturing [21-25]. Scientists have made enormous efforts for the production of titaniumtantalum alloys by arc melting in a high-frequency induction furnace. Because of the large discrepancies in melting point and 
density values of $\mathrm{Ti}$ and $\mathrm{Ta}$, Ti-Ta alloys used to be remelted many times to obtain a homogeneous elemental composition, which entailed a long processing time. The challenge in the production process by the melting technique suggests that fabrication of the alloy by powder metallurgy is a reasonable option because it is a complete and simple technique that implies the fractionation and synthesis of the alloy. Although melting, powder metallurgy and mechanical alloying are able to manufacture Ti-Ta alloy ingots with good performances, it is however difficult to fabricate Ti-Ta alloy products with personalized complex shapes. Selective laser melting, SLM is a powder melting additive manufacturing AM process, can fabricate complex metallic devices directly from CAD models with a layer-by-layer method.

\section{Microstructure Characterization}

Tantalum has an $\alpha$-BCC crystal structure and is an isomorphic $\beta$-stabilizer of titanium, which implies that the lattice pattern of the alloying element (tantalum in this case) is identical to the lattice pattern of the body-centered $\beta$-phase of titanium, BCC $[26,27]$. The $\alpha$ ' phase is a distorted, hexagonal, closed-packet crystal framework which results from the uncompleted diffusion less conversion of the $\beta$-phase to the $\alpha$ phase [28]. The $\alpha$ 'phase is stabilized by the addition of up to $10 \%$ or $20 \%$ Ta [29]. The $\alpha^{\prime \prime}$ phase is an orthorhombic martensitic crystal framework formed by the rapid cooling or quenching of Ti or Ti alloys from above the beta transus to below the beta transus [30]. There are experimental data that above $80 \%$ Ta s homogenous $\beta$-phase was stabilized $[6,7,27,29]$. The $\omega$ phase with the closed hexagonal HCP structure can be formed as a result of either $\beta$-zone cooling or during aging of quenched $\mathrm{Ti}$ alloys [31].

Thus, it is well established that in binary titanium-tantalum alloys there are only two stable solid phases ( $\alpha$ and $\beta$ ) and four non-equilibrium solid phases (martensite $\alpha^{\prime}, \alpha^{\prime \prime}, \omega$ and metastable $\beta$ phase) $[19,27]$. The formation of one phase or other depends on Ta content and posterior treatment of the alloy.

The microstructures of the Ti-Ta alloys were analyzed by X-ray diffraction analysis (XRD), scanning electron microscopy (SEM) and transmission electron microscopy (TEM). Metallographic examinations were also carried out to determine the as received and heat-treated microstructures [13].

\section{Mechanical Properties}

The tantalum concentration plays an essential contribution to the mechanical properties of Ti-Ta alloys. It is assumed that higher Ta concentration is not necessarily better for the improvement of the mechanical properties of titanium-tantalum alloys. Hardness values as a function of aging temperature were determined [6$8,13,15,32$ ] and varies from $175 \mathrm{HV} 7$ for Ti-10Ta to $743 \pm 12.93$ for Ti-25Ta heat treated at $900{ }^{\circ} \mathrm{C}$ for 30 minutes. Dynamic Young's modulus and tensile tests were carried out on Ti-Ta alloys [3,6,8$11,14,15,21,33]$. The Young's modulus varies from $64 \mathrm{GPa}$ for Ti-
$25 \mathrm{Ta} 3$ to $110 \mathrm{GPa}$ for Ti-10Ta obtained by selective laser melting (SLM) [8]. The ultimate tensile strength has values from $500 \mathrm{MPa}$ for Ti-10Ta 5 to $1029 \pm 8$ MPa for Ti-25Ta 15 .

The wear resistance of Titanium-Tantalum alloys and the biocompatibility were evaluated by assessing cytotoxicity through the MTT assay [7]. Between these techniques, to detect transus beta, electrical resistivity is a very accurate tool for measuring structural variations in Ti-based alloys $[34,35]$.

\section{Corrosion Resistance}

Corrosion resistance of Ti-Ta alloys was validated by different $\mathrm{dc}$ techniques as open-circuit potential measurements, linear polarization, potentiodynamic polarization and coulometric zone analysis $[6,7,12,13,15,36,37]$.

The electrochemical impedance spectroscopy (EIS) is employed to describe the performance of various metals and alloys in diverse media and to supply new information that could not previously be acquired with traditional direct current methods 38. Although there has been a substantial volume of research using EIS to analyze biomaterials, there are only a few with respect to EIS measurements on Ti-Ta alloys and Ti-Ta alloys [12,37,39].

It is noted that it is critical for all cases to develop proper impedance models, which can be employed to fit the experimental data and obtain the parameters that describe the corrosion process [38,39].

\section{Conclusion}

Ti-Ta alloys have not yet been widely adopted in medical applications and the primary reason is the difficulty in combining these two metals; in recent years, additive manufacturing processes have been successfully developed and approved for the fabrication of biomedical devices, including for Ti-Ta alloys. But detailed research on the effect of Ta concentration on the microstructure and performance of Ti-Ta alloys processed by additive manufacturing is still limited.

\section{Acknowledgement}

None.

\section{Conflict of Interest}

No conflict of interest.

\section{References}

1. Chen Q Thouas GA (2015) Metallic implant biomaterials. Mater Sci Eng R Reports 87: 1-57.

2. Biesiekierski A, Wang J, Abdel-Hady Gepreel M, Wen CA (2012) New look at biomedical Ti-based shape memory alloys. Acta Biomater 8: 16611669.

3. Zhou YL, Niinomi M (2009) Ti-25Ta alloy with the best mechanical compatibility in Ti-Ta alloys for biomedical applications. Mater Sci Eng C 29(3): 1061-1065.

4. Zhou YL, Niinomi, M, Akahori T, Fukui H, Toda H (2005) Corrosion resistance and biocompatibility of Ti-Ta alloys for biomedical applications. Mater Sci Eng A 398: 28-36. 
5. Zhou YL, Niinomi M, Akahori T (2008) Changes in mechanical properties of Ti alloys in relation to alloying additions of Ta and Hf. Mater Sci Eng A 483-484: 153-156.

6. Zhou YL, Niinomi M, Akahori T (2004) Effects of Ta content on Young's modulus and tensile properties of binary Ti-Ta alloys for biomedical applications. Mater Sci Eng A 371: 283-290.

7. DM Gordin, E Delvat, R Chelariu, G Ungureanu, M Besse et al. (2008) Characterization of Ti-Ta alloys synthesized by cold crucible levitation melting. Adv Eng Mater 10: 714-719.

8. Zhou YL, Niinomi M, Akahori T, Fukui H, Toda H (2005) Corrosion resistance and biocompatibility of Ti-Ta alloys for biomedical applications. Mater Sci Eng A 398: 28-36.

9. Huang S, Sing SL, de Looze G, Wilson R, Yeong WY (2020) Laser powder bed fusion of titanium-tantalum alloys: Compositions and designs for biomedical applications. J Mech Behav Biomed Mater 108: 103775.

10. Chen G, Yin J, Zhao S, Tang H, Qu X (2019) Microstructure and tensile properties of a Ti-28Ta alloy studied by transmission electron microscopy and digital image correlation. Int J Refract Met Hard Mater 81: 71-77.

11. Zhou YL, Niinomi M, Akahori T (2004) Decomposition of martensite $\alpha^{\prime \prime}$ during aging treatments and resulting mechanical properties of Ti-Ta alloys. Mater Sci Eng A 384: 92-101.

12. Mareci D, Chelariu R, Gordin DM, Ungureanu G, Gloriant T (2009) Comparative corrosion study of Ti-Ta alloys for dental applications. Acta Biomater 5: 3625-3639.

13. EA Trillo, C Ortiz, P Dickerson, R Villa, SW Stafford. et al. (2001) Evaluation of mechanical and corrosion biocompatibility of TiTa alloys. Mater Sci Mater Med 12: 283-292.

14. Zhou YL, Niinomi M (2008) Microstructures and mechanical properties of Ti-50 mass\% Ta alloy for biomedical applications. J Alloys Compd 466 535-542.

15. Danlei Zhao,Changjun Han,Yan Li,Jinging Li,Kun Zhou. et al. Improvement on mechanical properties and corrosion resistance of titanium-tantalum alloys in-situ fabricated via selective laser melting. $J$ Alloys Compd 804: 288-298.

16. Margevicius RW, Cotton JD (1998) Stress-assisted transformation in Ti60 Wt pct Ta alloys. Metall Mater Trans A Phys Metall Mater Sci 29: 139147.

17. JO Yin, G Chen, SY Zhao, Y Ge, ZF Li, et al. (2017) Microstructural characterization and properties of Ti-28Ta at.\% powders produced by plasma rotating electrode process. J Alloys Compd 713: 222-228.

18. Barzilai S, Hayun S (2015) Mechanical alloying and thermal analysis of Ta-Ti alloys. J Mater Sci 50: 6833-6838.

19. MehdiShahedi Asl, Seyed Ali Delbari, Maziyar Azadbeh, Abbas Sabahi Naminid, Mehdi Mehrabian, et al. (2020) Nanoindentational and conventional mechanical properties of spark plasma sintered Ti-Mo alloys. J Mater Res Technol 9: 10647-10658.

20. Sing SL, Yeong WY, Wiria FE (2016) Selective laser melting of titanium alloy with $50 \mathrm{wt} \%$ tantalum: Microstructure and mechanical properties. J Alloys Compd 660: 461-470.

21. Sing SL, Wiria FE, Yeong WY (2018) Selective laser melting of titanium alloy with $50 \mathrm{wt} \%$ tantalum: Effect of laser process parameters on part quality. Int J Refract Met Hard Mater 77: 120-127.

22. Nicolas Soro, Hooyar Attar, Erin Brodie, Martin Veidt, Andrey Molotnikov, et al. (2019) Evaluation of the mechanical compatibility of additively manufactured porous Ti-25Ta alloy for load-bearing implant applications. J Mech Behav Biomed Mater 97: 149-158.

23. Huang S, Sing SL, de Looze G, Wilson R, Yeong WY (2020) Laser powder bed fusion of titanium-tantalum alloys: Compositions and designs for biomedical applications. J Mech Behav Biomed Mater 108: 103775 (2020).

24. Dutta B, Froes FH (2017) Additive manufacturing of titanium alloys. in Additive Manufacturing Handbook: Product Development for the Defense Industry.

25. Fuerst J, Medlin D, Carter M, Sears J, Voort G Vander (2015) LASER Additive Manufacturing of Titanium-Tantalum Alloy Structured Interfaces for Modular Orthopedic Devices 67

26. Barzilai S, Toher C, Curtarolo S, Levy O (2016) Evaluation of the tantalum-titanium phase diagram from ab-initio calculations. Acta Mater 120: 255-263.

27. Peters M, Leyens C (2003) Titanium and Titanium Alloys: Fundamentals and Applications. Titanium and Titanium Alloys Fundamentals and Applications.

28. Dobromyslov AV, Dolgikh GV, Dutkevich Y, Trenogina TL (2009) Phase and structural transformations in Ti-Ta alloys. Phys Met Metallogr 107: 502-510.

29. Li C, Li G, Yang Y, Varlioglu M, Yang K (2011) Martensitic Twinning in Alpha + Beta Ti-3.5Al-4.5Mo Titanium Alloy. J Metall, 1-5.

30. Chen G, Yin J, Zhao S, Tang H, Qu X (2019) Microstructure and tensile properties of a Ti-28Ta alloy studied by transmission electron microscopy and digital image correlation. Int J Refract Met Hard Mater 81: 71-77.

31. Dercz G, Izabela Matula, Zubko Maciej, Alicja Kazek-Kesik, Maszybrocka Joanna, et al. Synthesis of porous Ti-50Ta alloy by powder metallurgy. Mater Charact 142: 124-136.

32. Buciumeanu M, Bagheri A, Souza JCM, Silva FS, Henriques B (2016) Tribology International Tribocorrosion behavior of hot pressed CoCrMo alloys in arti fi cial saliva. Tribiology Int 97: 423-430.

33. S Mendis, W Xu, HP Tang, LA Jones, D Liang, et al. (2020) Applied Surface Science Characteristics of oxide films on Ti- (10 - 75 ) Ta alloys and their corrosion performance in an aerated Hank' s balanced salt solution. 506.

34. Wu C, Peng P, Chou H, Ou K (2018) Microstructural, mechanical and biological characterizations of the promising titanium-tantalum alloy for biomedical applications. J Alloys Compd 735: 2604-2610.

35. Gloriant T, G Texier, F Prima, D Laillé, DM Gordin, et al. (2006) Synthesis and Phase Transformations of Beta Metastable Ti-Based Alloys Containing Biocompatible Ta, Mo and Fe Beta-Stabilizer Elements. 8(10): 961-965

36. Mareci D, Chelariu R, Gordin DM, Ungureanu G, Gloriant T (2009) Comparative corrosion study of Ti-Ta alloys for dental applications. Acta Biomater 5: 3625-3639.

37. Gloriant T, G Texier, F Prima, D Laillé, DM Gordin, et al. (2006) Synthesis and Phase Transformations of Beta Metastable Ti-Based Alloys Containing Biocompatible $\mathrm{Ta}$, Mo and $\mathrm{Fe}$ Beta-Stabilizer Elements. 8(10): 961-965

38. Scully J, Silverman D, Kendig M (1993) Electrochemical Impedance: Analysis and Interpretation. 45(10): 582-582.

39. Liu Y, Kaiyang Li, Hong Wu, Min Song, Wen Wang, et al. (2015) Synthesis of Ti-Ta alloys with dual structure by incomplete diffusion between elemental powders. J Mech Behav Biomed Mater 51: 302-312. 